MODELING, IDENTIFICATION AND CONTROL, 2005, vOL. 26, No. 2, 81-94

doi:10.4173/mic.2005.22

\title{
Active Feedback Control of Unstable Wells at the Brage Field*
}

\author{
M. DALSMO, SPE, ABB; E. HALVORSEN, Norsk Hydro ASA; \\ O. SLUPPHAUG, ABB
}

Keywords: Unstable wells, active feedback control, oil production, gas lift, stabilization

\begin{abstract}
In this paper we will present new results on stabilization of horizontal wells with gas lift. The stabilization is achieved by a novel dynamic feedback control solution using the production choke at the wellhead. The primary input to the dynamic feedback controller is a measurement of the downhole pressure.

The field results to be presented are from the Brage field operated by Norsk Hydro in the North sea. Production at Brage began in 1993 and the field went off plateau in 1998. As the production has decreased, the problems related to unstable production from some of the wells have escalated steadily.

The results from the extensive field tests on the Brage wells are very promising. The tests have confirmed the stabilization feature of the control solution. The pressure and flow variations have been dramatically reduced, and it is possible to produce the wells at a lower downhole pressure leading to increased production.
\end{abstract}

\section{Introduction}

With most oil and gas fields in the western world becoming mature, the industry is having to face a new reality: How to increase, or at least stabilize, production while maintaining available reserves at their present level. Indeed, unstable production in multiphase production systems pipelines can cause serious and troublesome operational problems for downstream receiving production facilities. Three approaches are conventionally practiced to manage the instabilities in wells: choking the flow, increasing the gas lift rate, or providing overcapacity to accommodate the gas and liquid slugs that are produced in an erratic manner. All these classical approaches imply inefficient production or expensive over-design. In most cases, too much gas is injected into the gas lifted wells or the production rate is not maximized. In more extreme cases the unstable

*Copyright 2002, Society of Petroleum Engineers Inc. SPE 77650.

This paper was prepared for presentation at the SPE Annual Technical Conference and Exhibition held in San Antonio, Texas, 29 September-2 October 2002.

This paper was selected for presentation by an SPE Program Committee following review of information contained in an abstract submitted by the author(s). Contents of the paper, as presented, have not been reviewed by the Society of Petroleum Engineers and are subject to correction by the author(s). The material, as presented, does not necessarily reflect any position of the Society of Petroleum Engineers, its officers, or members. Papers presented at SPE meetings are subject to publication review by Editorial Committees of the Society of Petroleum Engineers. Electronic reproduction, distribution, or storage of any part of this paper for commercial purposes without the written consent of the Society of Petroleum Engineers is prohibited. Permission to reproduce in print is restricted to an abstract of not more than 300 words; illustrations may not be copied. The abstract must contain conspicuous acknowledgment of where and by whom the paper was presented. Write Librarian, SPE, P.O. Box 833836. Richardson. TX 75083-3836. U.S.A.. fax 01-972-952-9435. 
well has to be shut in. In such situations even re-completion for decreasing the tubing size may be considered. However, this is an expensive alternative.

Oil wells with long horizontal bores, and also gas lift wells, tend to behave erratically under certain operating conditions. Unstable production has many drawbacks. For example, surge hinders smooth operation and calls for safety measures and means of guarding against shutdown. Also, the total oil and gas production must be within the system's design capacity to provide adequate safety margins. Instability can sharply reduce lift gas efficiency, while difficulties with gas lift allocation computation are also common. Well instabilities also make it impossible to distribute the lift gas optimally. All in all, unstable wells are difficult to operate efficiently.

At Brage a new approach for stabilization is now currently being tested. The new method is based on dynamic active feedback control of the production choke at the wellhead. Initial field tests were done in October 2000 and in March 2001 on the first candidate well; a horizontal gas lift well with a downhole pressure gauge. After these initial experiments, a two-months test was carried out from August 2001 to October 2001 on a similar well that had been shut in for three months due to severe slugging. In the present paper we will present the results from this extensive test.

\section{Brage Field Development \\ General Overview}

The Brage Field is located in the Norwegian sector of the North Sea and is operated by Norsk Hydro. Production commenced in September 1993 from five predrilled wells tied back to the steel jacket platform. The two main reservoirs, Fensfjord and Statfjord, are located at approximately 2100 and $2300 \mathrm{~m}$ TVD and consist of Jurassic age sandstones. One well has been drilled and completed in the Sognefjord reservoir, located in the north-eastern part of the field.

The three individual reservoirs exhibit significant differences with respect to reservoir properties and drainage philosophy. Figure 1 shows a structural cross section of the Brage field.

Statfjord is characterized by massive, relatively homogeneous, permeable (1-2 Darcy) reservoir sands, with occasional thin layers of shale and calcite. Zone thickness above initial Oil Water Contact (OWC) averages 50 meters TVD. The homogenous character of Statfjord gives an excellent lateral pressure transmissibility, where pressure support to the six oil production wells is facilitated by two high rate water injectors perforated at or below initial OWC. The practical absence of an aquifer makes reservoir pressure very sensitive to the production/injection material balance. Reservoir pressure in Statfjord is normally kept between 200-220 bar. Artificial lift is necessary to maintain production at present watercuts $(55-90 \%)$.

Fensfjord consists of thin (1-5 m) sands of moderate to poor permeability, separated by layers of shale/siltstone and calcite. Total Fensfjord thickness is $30 \mathrm{~m}$ TVD, with a Net/Gross ratio of 0.3 . Significant faulting combined with low permeability $(1-100 \mathrm{mD})$ and low vertical transmissibility gives considerable pressure gradients between injection (Pwf 300 bar) and production (Pwf 40-80 bar) wells. The heterogeneous character of Fensfjord has resulted in increased well density, relative to initial plans but the total recovery target is still only $24 \%$. 
Sognefjord located at relatively shallow depth of $2000 \mathrm{~m}$ TVD SS, is produced by a single depletion drive horizontal well. Reservoir properties are variable, with permeabilities occasionally in the 1-2 Darcy region in streaks. Water injection has been considered unnecessary due to the presence of a natural gas cap. However, the oil column is only $16 \mathrm{~m}$, and the total recovery factor is expected to be $<10 \%$.

The Brage platform is equipped with a two stage separation system incorporating gas compression/export facilities to Statpipe and oil export via Oseberg Field Centre. Water injection is the main drive mechanism at Brage. A WAG-scheme was implemented for several of the Fensfjord flank injectors shortly after field start up.

Platform 1st stage separator inlet pressure is $7.5 \mathrm{bar}(100 \mathrm{psi})$, which is significantly lower than most of the other Norwegian offshore fields. Low backpressure combined with extensive use of gaslift has enabled high well rates from the low productive and depleted Fensfjord formation.

More general information about the Brage field development may be found in Lien et al. (1998) and Andersen et al. (2000).

\section{Completion design at Brage}

The completion design of well 31/4-A-21, a typical Fensfjord oil producer is shown in Figure 3. The reservoir section is $1500 \mathrm{~m}$ long, and due to the stratified nature of the Fensfjord reservoir the well was planned and drilled in a U-shape Figure 2. This ensured that the well penetrated all oil filled geological layers. To avoid sand production the well was completed with a $200 \mathrm{gmm}$ single wire wrapped (SWW) sand-screen in open hole. Furthermore, the well was divided into five separate intervals using four external casing packers. Within each interval one to three sliding sleeves provided communication with the reservoir. The purpose of the completion design was to allow for selective zonal isolation if a production log could later identify excessive gas or water production.

The well is completed with $7^{\prime \prime}$ tubing, with two gas lift mandrels installed (a dummy valve in the upper mandrel and a gas lift valve in the lower mandrel). Because of the high gas compressor outlet pressure on Brage (220 bar), there is no need for unloading valves. This makes the gas lift design easier. The lower gas lift mandrel is set on maximum wire line depth (i.e. less than 65 degrees deviation), or just above the production packer if the maximum deviation is less than 65 degrees. Only the sizing of the valve requires additional design. Since 1995 all new wells have been completed with downhole pressure gauges. These are powerful tools for optimizing gas lift, because optimization of each well can be done without the use of the test separator, and the response from changing the flow condition is monitored immediately in the downhole gauge. They also make an important contribution to the reservoir analysis and calibration of the simulation models.

\section{Unstable Production at Brage}

The production at Brage is limited by the water and gas capacities, and the field is today producing $8000 \mathrm{Sm} 3 / \mathrm{d}$ of oil. Great effort is put into optimizing the production to fully utilize the process capacities at the platform. Daily communication between offshore and onshore organization is maintained for short-term optimization. However the production is also restricted by instability in the process train. This instability are caused by erratic flow manner from the oil producing wells. This implies that the operators need to take slugging into account when running the process to avoid trips and 
shutdown of the process train. The process train is therefore run on a lower capacity than design.

The low reservoir pressure in the central area of the Fensfjord formation in combination with high water cut $(>50 \%)$ and low GOR $(93 \mathrm{Sm} 3 / \mathrm{Sm} 3)$, makes artificial lift necessary to maintain production. Gas lift is used for that purpose. The gas lift gas that is used is circulated in the compressor train and takes up 50\% of the total capacity making production optimization even more important. Except from two wells, all Brage wells are run on continuous gas lift.

The optimization of the gas lift has been a challenge on Brage. Especially the U-shaped "horizontals" with 7 inch tubing have been showing erratic flow behavior. On average the compressor has been run $10 \%$ below its maximum capacity to be able to handle the fluctuations from the gas lifted wells. Including the 50 to $150000 \mathrm{std} \mathrm{m} / \mathrm{d}$ from gas lift, each of these wells has produced 200 to $300000 \mathrm{std} \mathrm{m}^{3} / \mathrm{d}$ of gas, giving a total GOR in the range of 200 to $350 \mathrm{std} \mathrm{m}^{3} / \mathrm{std} \mathrm{m}^{3}$ The fluctuation in the process system is also causing non optimum conditions on the water handling side.

Casing heading was experienced in the first gas lift wells, and the gas lift valves were redesigned to a new Venturi-type gas lift valve with a smaller flow area. These valves give critical flow over the valve for the whole operational range, thus eliminating casing heading. The redesign of the gas lift valve and change of tubing design to $5 \frac{1}{2}$ "tubing has improved the erratic flow behavior, but still slugging occurs. However, the current slugging problem in the Brage wells is not casing heading Low rates in the well below the gas lift entry point lead to separation of the different phases in the well causing backflow of water and slugs to be formed in the well. The U-shape of the well is also believed to contribute to the slugging by setting up terrain slugs and acting as a liquid block when low rates are encountered.

\section{Active Feedback Control of a Production Well \\ Feedback Control Fundamentals}

Feedback control means that the settings of one or more controls in a system, e.g. valve openings or set points for pressures, temperatures, levels or flows, are based on readings of one or more measurements in the same system. Feedback control can be automatic or manual. Manual feedback control means that the decision on the setting of the controls is done by a human, while automatic feedback control means that the decision is made by some device. The device could be mechanically based, electrically based, electronically based, hydraulically based or a combination thereof. Of course, there is an abundance of examples of both manual and automatic feedback control related to oil production.

\section{Related Work}

Typically, wellhead and pipeline choke settings have been controlled by manual feedback. Recent results demonstrating the feasibility and the potential of applying dynamic feedback control to unstable multiphase flow like severe slugging in multiphase pipelines and casing heading in gas lifted wells can be found in Jansen et al. (2001); Havre et al. (2000); Hedne \& Linga (1990); Henriot et al. (1999); Lemetayer \& Miret (1991); Garnaud et al. and Courbot (1996). 


\section{Explanation of the General Principle}

In Figure 4 the general concept of automatic feedback control of a production well is illustrated. In this paper we will refer to this general concept as active feedback control of a well. Wells with natural flow are controlled by automatic actuation of the production choke, and in the case of gas-lifted wells the gas injection choke may also be automatically controlled. An automatic feedback control solution for a production well generally uses pressure and temperature data from the production tubing, and for gas lifted wells measurement data taken from the annulus may also be used. used. Pressures in the production tubing may be measured anywhere between the bottom of the well and the wellhead. The pressure downstream of the production choke may also be used. The input from the operator to the active well controller is typically a setpoint for e.g. the downhole pressure.

\section{A-21 Well Test with Manual Control in May 2001}

In the end of April 2001, it was reported that Brage well A-21 was just producing gas. As a consequence, the well was shut in for a short period of time and started up again in the beginning of May 2001. The fist attempt to start up the well did not succeed due to severe slugging nearly tripping the test separator as well as the separator train.

In the second attempt to start up the well, other unstable wells were shut in to provide buffer capacity to be able to handle slugs from A-21 in the separator train. In Figure 7 the A-21 choke opening during the test period is shown. At time $=10$ hours a gas lift rate of $2000 \mathrm{Sm}^{3} / \mathrm{h}$ was established in the well (cf. Figure 8 and Figure 9 showing the gas lift injection rate and the gas lift pressure respectively) with a choke opening of $15 \%$. At this level the downhole pressure (Figure 10) was fluctuating between 74 and 82 bar. The wellhead pressure(see Figure 11) varied approximately between 10 and 30 bar. As a result of this, the operator constantly had to be on the alert for avoiding trips. The gas lift rate was then increased to around $3000 \mathrm{Sm}^{3} / \mathrm{h}$ between time $=20$ hours and time $=25$ hours (see Figure 8 and Figure 9). From time $=22$ hours the choke was opened gradually to approximately $22.5 \%$. In this last part of the test period, the well behavior became even worse than in the first part, with pressure variations downhole and at the wellhead in the order of $10 \mathrm{bar}$ and 20 bar respectively. The slug period was approximately 75 minutes by the end of the test.

During the test. the well was producing to the test separator and the resulting oil, water and gas rates at the outlet of the test separator are shown in Figure 12, Figure 13 and Figure 14. It should be noted that the huge slugs that were produced into the test separator, resulted in uncertain oil and water measurements due to poor separation of the oil and water phases. Even so, it can be concluded from the plots in Figure 12 and Figure 13 that the well was producing severe liquid slugs in the test period. The slugs were so big that it was decided to shut well A-21 in again. It was not possible to produce from the well due to a high risk of trips and extensive flaring.

After the well test in May it was decided to execute test operation of active well feedback control on well A-21. The start-up of the test operation was scheduled for August 2001.

\section{A-21 Field Results with Active Feedback Control}

Description of Active Well Control Hardware on A-2I

In Figure 5 the active feedback control principle that was tested on well A-21 is 
illustrated. The downhole pressure measurement taken at MD $3179 \mathrm{~m}$ was feed back to the active well controller together with the wellhead pressure measurement and a measurement of the pressure downstream the choke. These pressure measurements are then used to continuously calculating calculate the choke opening of the production choke with the aim to stabilize the well production.

The production choke is equipped with a stepping actuator with 192 steps. The stroke time of the choke is about six minutes.

The active feedback control software is run in an ABB AC $800 \mathrm{M}$ controller communication with a Siemens Teleperm DCS (Distributed Control System) at Brage using the so-called Modbus protocol. The inputs from to the AC $800 \mathrm{M}$ controller are measurements of pressures and the output is a calculated production choke opening. The AC $800 \mathrm{M}$ controller may be accessed via an ABB PC, making it possible to monitor the behavior of the controller and to perform changes on-line as the controller software is running.

\section{Start-up of Active Feedback Control on A-21}

After being shut in since May 2001, A-21 was started up again on August 24, 2001. Some time after start up, the well became unstable, slugging in its characteristic manner.

After some initial tuning, active feedback control on well A-21 was activated on August 26, 2001 around $11 \mathrm{am}$. Prior to enabling the active well controller, the well was manually operated without success, and the well was slugging severely. Figure 15 shows the production choke opening in the time before and after the active well controller was activated. The corresponding downhole pressure and wellhead pressure are shown in Figure 16 and Figure 17 respectively. A rather short time after the activation of the active feedback controller just prior to time $=2.2$ days, the variations in both the downhole and wellhead pressure were eliminated. After the well was stabilized, the downhole pressure setpoint was decreased gradually, and around time $=3.7$ days a downhole pressure of 76 bar was reached. The commanded decrease in the downhole pressure setpoint and the resulting response in the downhole pressure are given in Figure 18. The corresponding production choke opening is shown in Figure 19. In addition, the resulting test separator oil and water rates are shown in Figure 20. At this level, the well was producing approximately $7 \mathrm{Sm}^{3} / \mathrm{h}=1057 \mathrm{bbl} / \mathrm{d}$ of oil and around $24 \mathrm{Sm}^{3} / \mathrm{h}=3620$ $\mathrm{bbl} / \mathrm{d}$ of water.

\section{Going from Active to Manual Control}

As the test operation evolved and the well characteristic of A-21 changed, it was difficult to keep the well at a downhole pressure level of 76 bar. Even with the active feedback controller in operation, it was not possible to totally eliminate the pressure variations in the downhole and wellhead pressures. In order to compare the behaviour of the well with and without active feedback control, the active well controller was deactivated on September 21, 2001; between time $=28$ days and time $=28.5$ days in Figure 21 .

The production choke opening in the period of manual control was below the average choke opening with active feedback control. Even so, just after the active well controller was deactivated, and the choke was frozen at its current position, the downhole pressure increased rapidly, and started to oscillate with a lower frequency and a higher amplitude than before (see Figure 22). The wellhead pressure variations also increased considerably 
while the frequency of the variations decreased, indicating that rather big liquid slugs now where produced (cf. Figure 23). Thus, the change in well behaviour resulted in rather severe problems in the process train, and between time $=28.5$ days and time $=29$ days it was decided to put the active feedback well controller into action again. Immediately after active feedback control was activated, the well started to calm down, and the well was then driven to its operation point of $78 \mathrm{bar}$ at the downhole pressure the next two days.

\section{Loss of Downhole Pressure Measurement}

On October 8 , the connection to the downhole pressure measurement was lost temporarily. In the period that the downhole pressure measurement was unavailable, the active well controller got a constant downhole pressure measurement as input (see Figure 24 , just before time $=45$ days). As the input to the active well controller appeared to be constant, the commanded choke position was also more or less constant (cf. Figure 25), resulting in a very noticeable change in the wellhead pressure measurement variations (cf. Figure 26 and Figure 27). Indeed, the amplitude of the wellhead pressure variations increases from a level of approximately 15 bar to 35 bar while the frequency of the variations decreased, again meaning that rather big liquid slugs now were produced. The downhole pressure measurement appeared again between time $=45$ days and time $=45.5$ days, and the downhole pressure had then reached a level of 82.5 bar. After the connection with the downhole pressure measurement again was established, the well was stabilized and brought back to its current level of operation at a downhole pressure of 79 bar.

\section{Further Work at Brage}

Unfortunately the connection to the downhole pressure sensor at A-21 was permanently lost in the middle of October 2001. As the active well feedback controller that was tested in the period from August 26 to October 11, 2001, relied on information from this sensor, the test operation on A-21 was temporarily stopped as a result of this. However, in Spring 2002 a new test program was initiated, involving the wells A-08, A-21, A-32. A-34 and A-39. Except from A-21, all the wells in the test program are equipped with a downhole pressure sensor. For A-21 a new concept not relying on a downhole pressure measurement will be tested, whereas for the other wells, information from the downhole sensor will be fully utilized.

\section{Conclusions}

In this paper we have presented promising field results with a novel concept for stabilization of unstable production from an oil well. The main ingredient in this concept is the application of active feedback control to the production choke, relying on a measurement of the downhole pressure as well as measurements of the pressures at the wellhead. On the test well, which was impossible to operate manually, the variations in the wellhead pressure were decreased significantly when active feedback control was in operation. In contrast to the situation with manual operation, it was not necessary to shut in the well for shorter or longer periods of time to build up pressure. Hence, as the well produced $900-1000 \mathrm{bbl} / \mathrm{d}$ in the test period, the benefit of employing active well control was quite obvious on this test candidate. 
produced $900-1000 \mathrm{bbl} / \mathrm{d}$ in the test period, the benefit of employing active well control was quite obvious on this test candidate.

\section{Acknowledgments}

The authors would like to thank the partners of the Brage field Norsk HydroASA, Statoil, Exxon Mobil, Fortum Petroleum and Paladin Resources(Norway) Limited for their kind permission to publish this article.

\section{References}

Andersen, K. I., Halvorsen, E., SÆLlensminde, T. \& Østby, N. O. (2000). Water Management in Closed Loop-Problems and Solutions at Brage Field, paper SPE 65162 presented at the 2000 SPE European Petroleum Conference held in Paris, France, 24-25 October 2000.

COURBOT, A. (1996). Prevention of Severe Slugging in the Dunbar $16^{\prime \prime}$ Multiphase Pipeline, paper OTC 8196 presented at the 1996 Offshore Technology Conference, Huston, Texas, May 1996.

Garnaud, F., Casagrande, M., Foullout, C. \& Lemetayer, P. (1996). New Field Methods for a Maximum Lift Gas Efficiency Through Stability, paper SPE 35555 presented at the 1996 European Prod. Opr. Conf., Stavanger, April 16-17.

Havre K. \& Dalsmo M. (2001). Active Feedback Control as the Solution to Severe Slugging, paper SPE 71540 presented at the 2001 SPE Annual Technical Conference \& Exhibition, New Orleans, Louisiana, 30 Sept.-3 Oct., 2001.

HaVRe, K., Stornes, K. O. \& Stray, H. (2000). Taming slug flow in pipelines, ABB Review, 4.

HEDNE, P. \& LINGA, H. (1990). Suppersion on Terrain Slugging with automatin and manual Riser choking, Advances in Gas-Liquid Flows, pp. 453-460.

Henriot, V., Cuorbot, A., Heintzé, E. \& MoyeuX, L. (1999). Simulation of Process to Control Severe Slugging: Application to the Dunbar Pipeline, paper SPE 56461 presented at the 1999 SPE Annual Technical Conference \& Exibition held in Huston, Texas Oct. 3-6 1999.

Jansen, B., Dalsmo, M., NøKleberg, L., Havre, K., Kristiansen, V. \& Lemetayer, P. (1999). Automatic Control of Unstable Gas Lifted Wells, paper SPE 56832 presented at the 1999 SPE Annual Technical Conference \& Exhibition, Houston, Texas, Oct. 3-6, 1999.

Jansen, B., Dalsmo, M., Stenersen, K., BuUne, B. \& MoE, H. (2001). New Upstream Control and Optimization Techniques Increase Return on Investment, ABB Review, 3, pp. 20-27.

LemetaYeR, P. \& Miret, P. M. (1991). Tool of the 90is To Optimize Gas-Lift Efficiency in the Gonelle Field, Gabon, paper SPE 23089 presented at the Offshore Europe Conference, Aberdeen, Sept. 3-6, 1991.

Lien. S. C., LiE, S. E, Fuellbirkeland, H. \& Larsen, S. V. (1998). Brage Field, Lessons Learned After 5 Years of Production, paper SPE 50641 presented at the 1998 SPE European Petroleum Conference held in Hague, The Netherlands, 20-22 October 1998. 


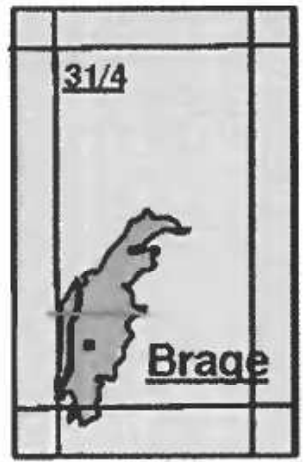

w

$E$

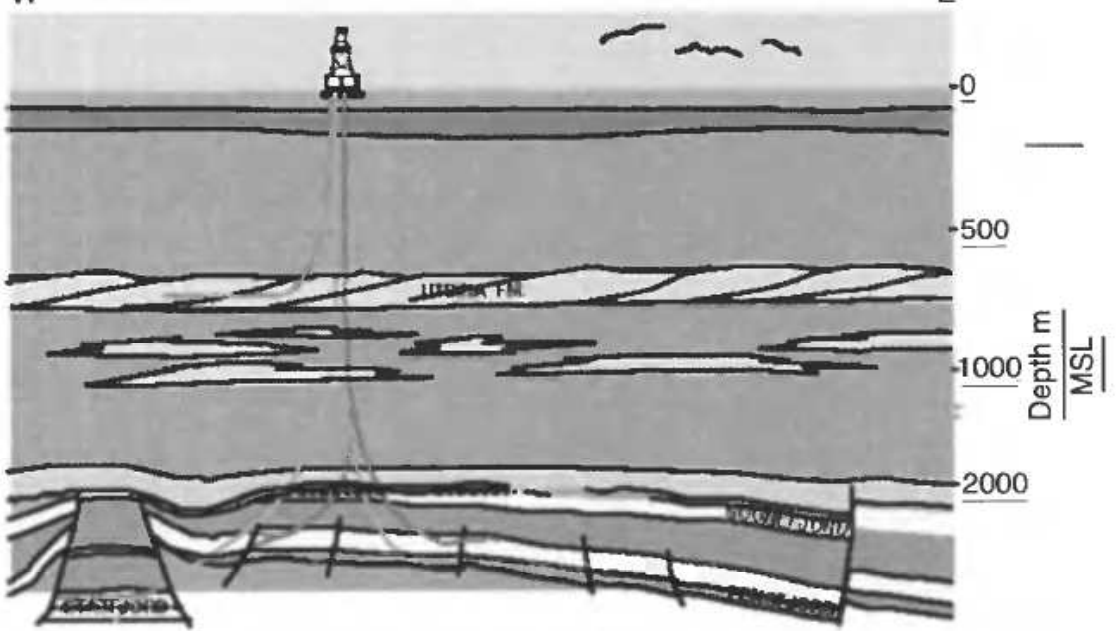

Figure 1. Brage structural cross section.

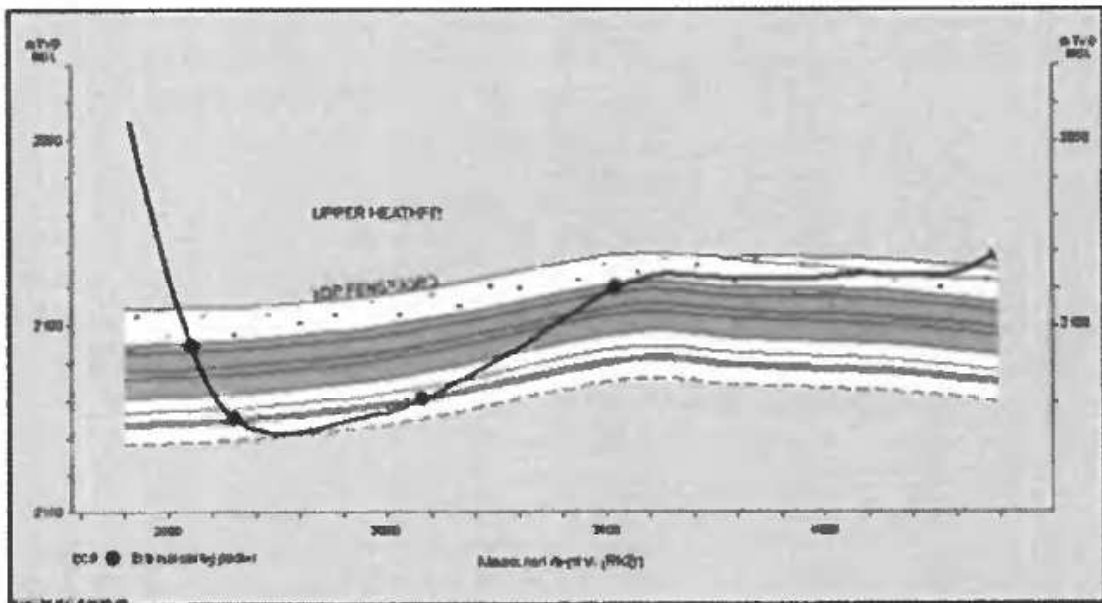

Figure 2. Reservoir section of a typical Fensfjord Oil Producer. 


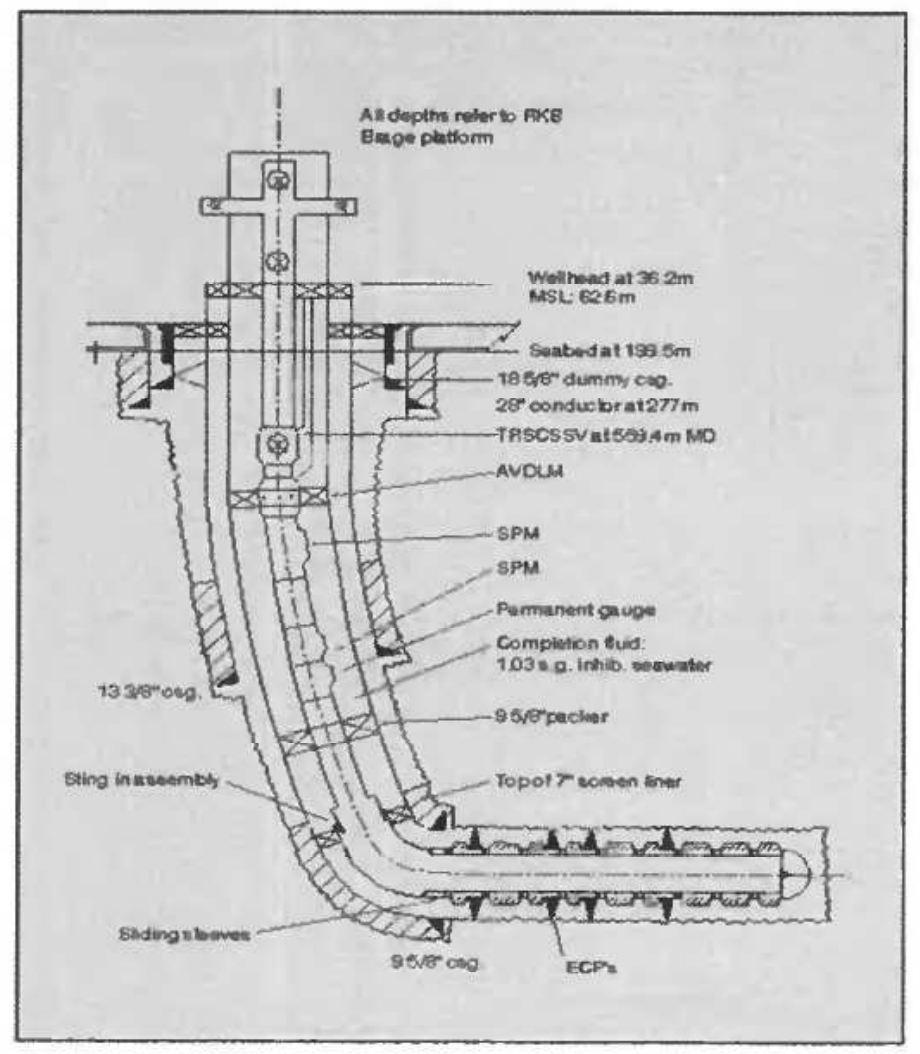

Figure 3. Fensfjord oil producer completion design.

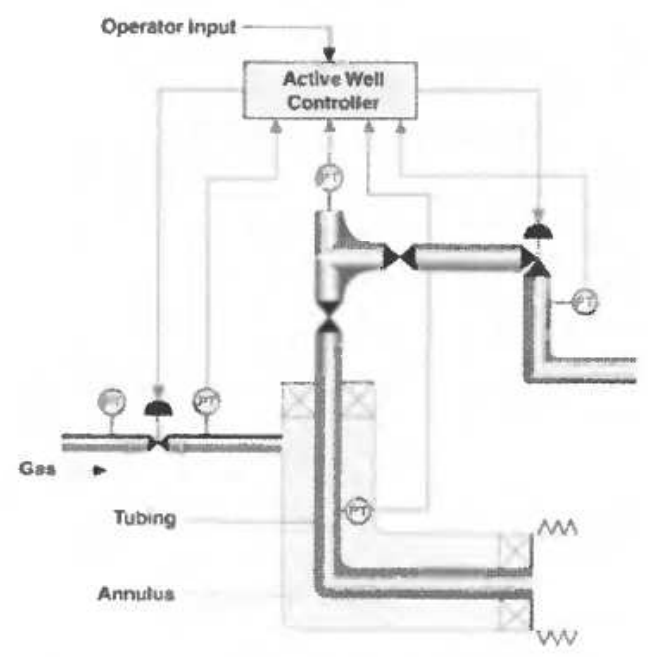

Figure 4. Illustration of active well control by automatic feedback. Generally, both the gas injection choke and the production choke may be automatically controlled simultaneously using available measurements at the surface, in the annulus and downhole to calculate the choke openings.

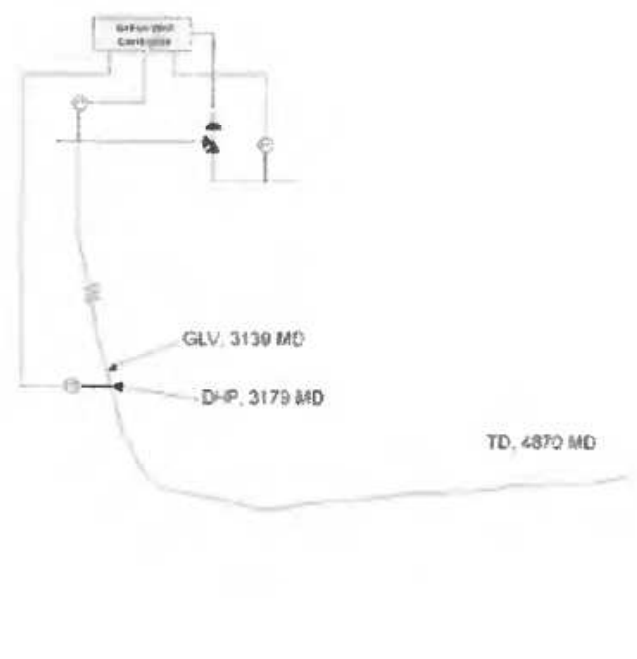

Figure 5. Concept drawing of active well control at Brage well A-21. The main input to the controller algorithm calculating the choke position is the downhole pressure measurement. In addition the pressure measurements at the wellhead and downstream the choke may be utilized. 


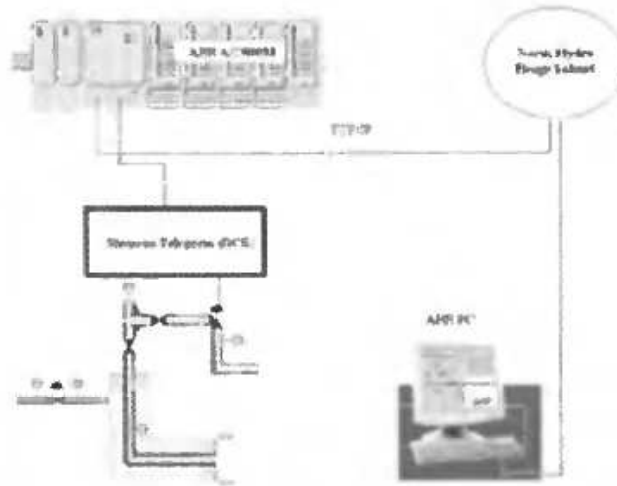

Figure 6. Active Well Control hardware set-up at Brage A-21. The production choke is controlled by an $\mathrm{AC} 800 \mathrm{M} \mathrm{ABB}$ controller via the Siemens DCS system at Brage. The ABB controller is accessed via a ABB PC on TCP/IP.

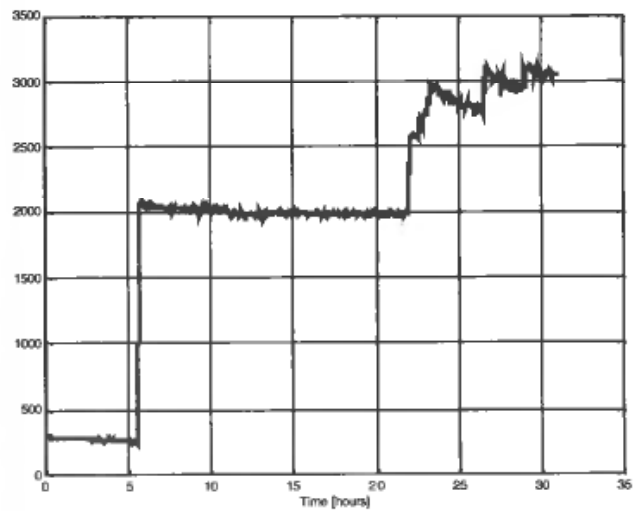

Figure 8. A-21 well test May 2001: Gas injection rate $\left[\mathrm{Sm}^{3} / \mathrm{h}\right]$.

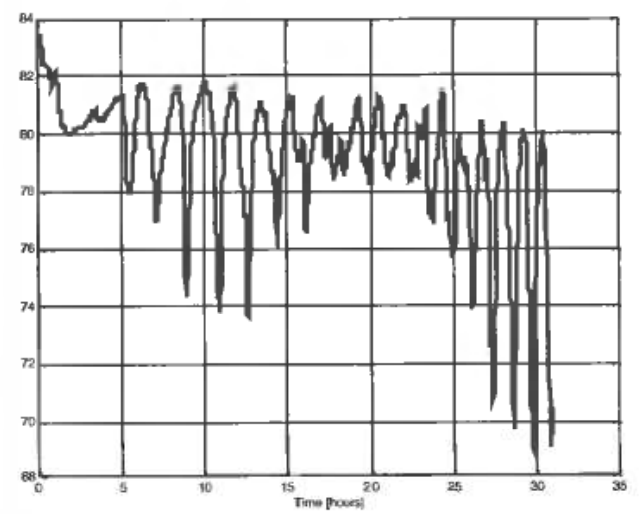

Figure 10. A-21 well test May 2001: Down hole pressure [bar].

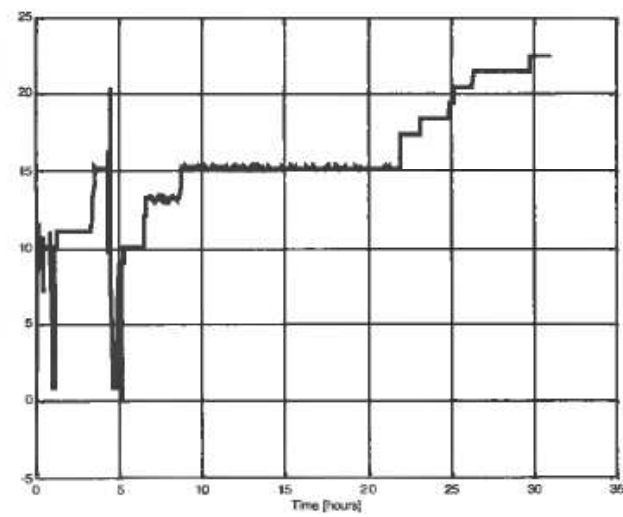

Figure 7. A-21 well test May 2001: Production choke opening $[\%]$. The well is operated manually (no active control).

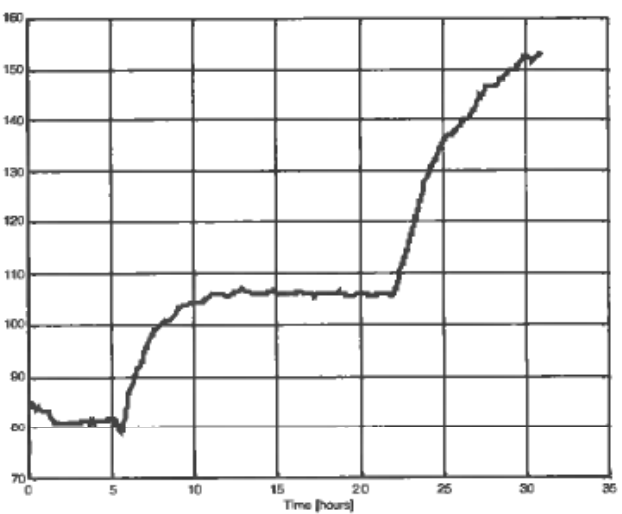

Figure 9. Well test May 11-12. 2001: Gas lift pressure [bar].

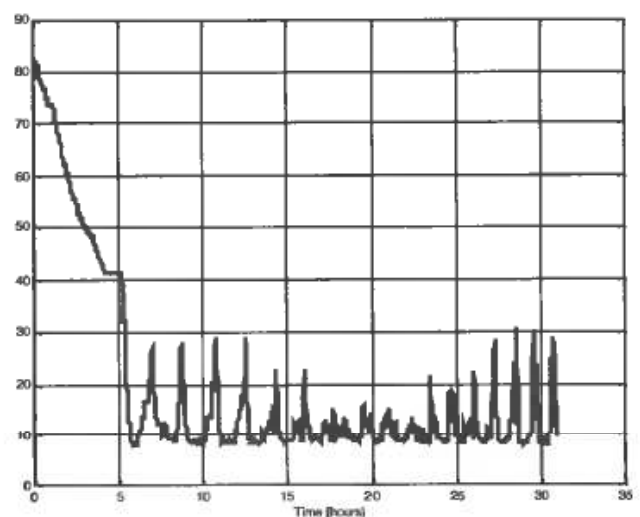

Figure 11. A-21 well test May 2001: Wellhead pressure [bar]. 


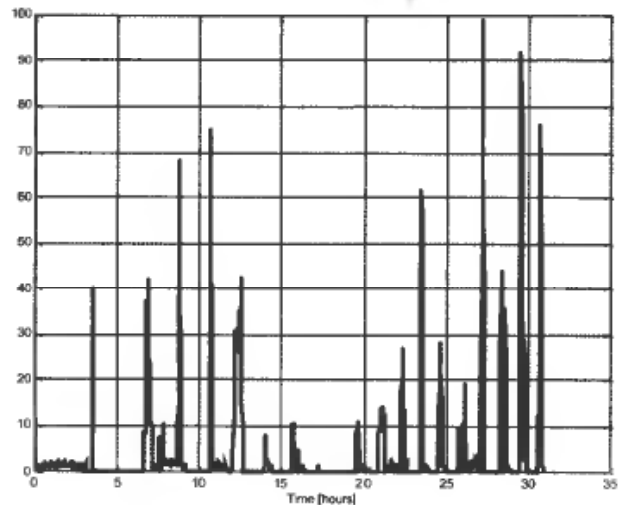

Figure 12. A-21 well test May 11-12, 2001: Test separator oil rate $\left[\mathrm{Sm}^{3} / \mathrm{h}\right]$.

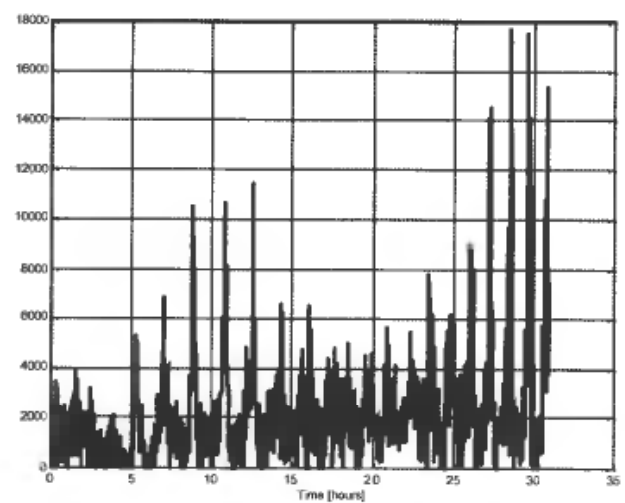

Figure 14. A-21 well test May 11-12, 2001: Test separator gas rate $\left[\mathrm{Sm}^{3} / \mathrm{h}\right]$.

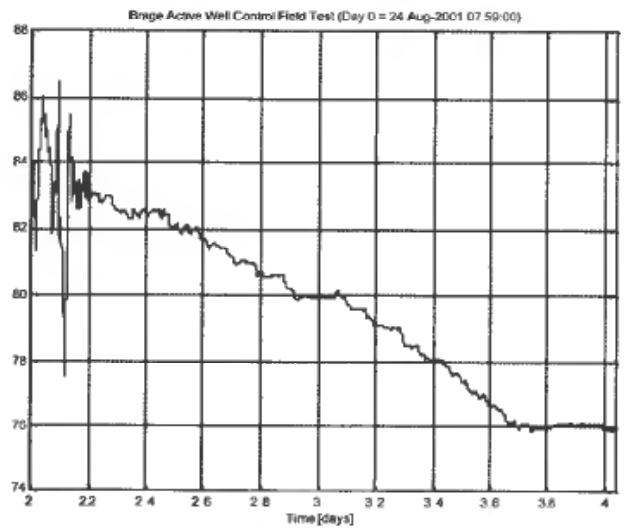

Figure 16. Downhole pressure $[\mathrm{bar}]$ in connection with start-up of active well feedback control on Brage well A-21.

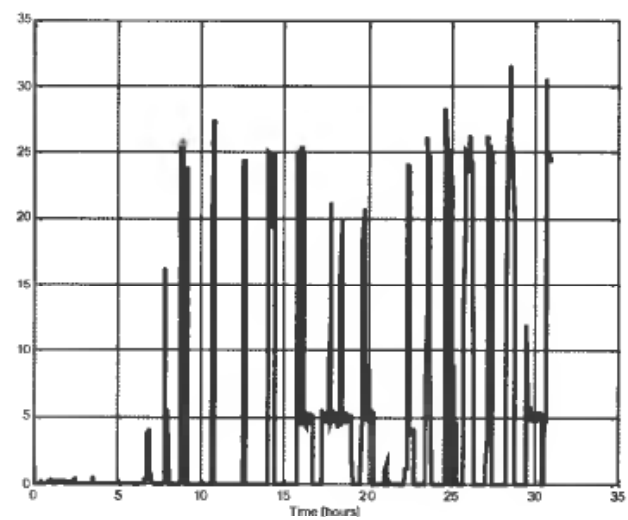

Figure 13. A-21 well test May 11-12, 2001: Test separator water rate $\left[\mathrm{Sm}^{3} / \mathrm{h}\right]$.

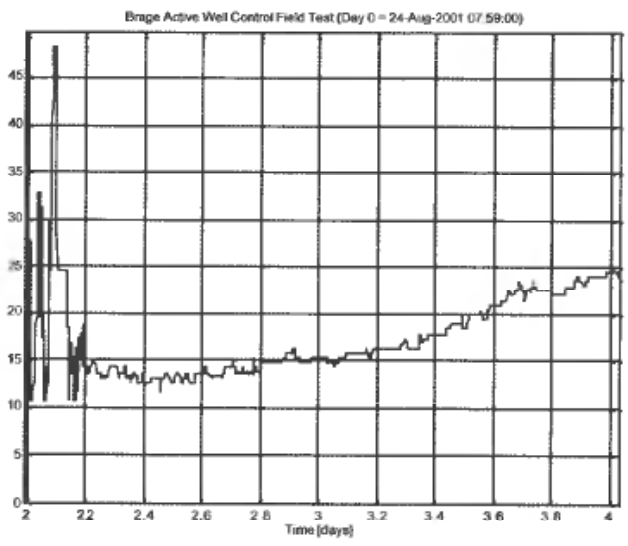

Figure 15. Production Choke opening [\%] in connection with start-up of active well feedback control on Brage well A-21:

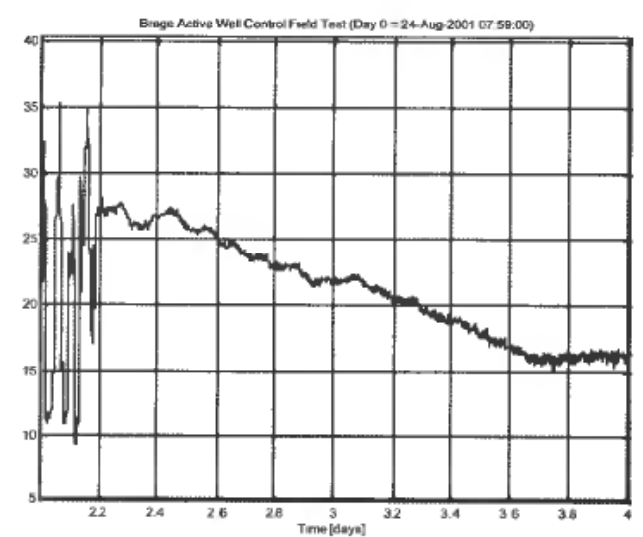

Figure 17. Wellhead pressure [bar] in connection with start-up of active well feedback control on Brage well A-21: 


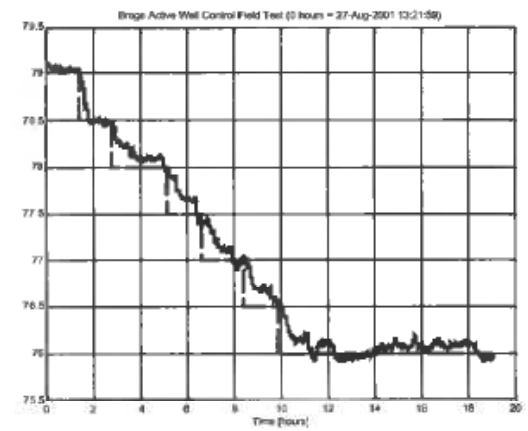

Figure 18. Decreasing the downhole pressure setpoint (dashed line) to the active well feedback controller. The downhole pressure [bar] decreases accordingly.

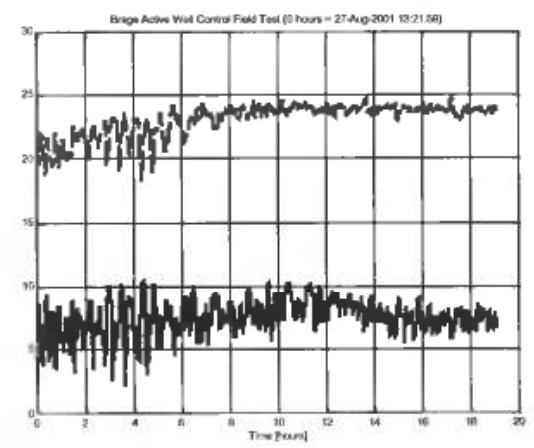

Figure 20. Test separator oil rate $[\mathrm{Sm} 3 / \mathrm{h}]$ and test separator water rate $[\mathrm{Sm} 3 / \mathrm{h}]$ (four hours moving average) corresponding to the downhole pressure and the choke opening in Figure 18 and Figure 19 respectively.

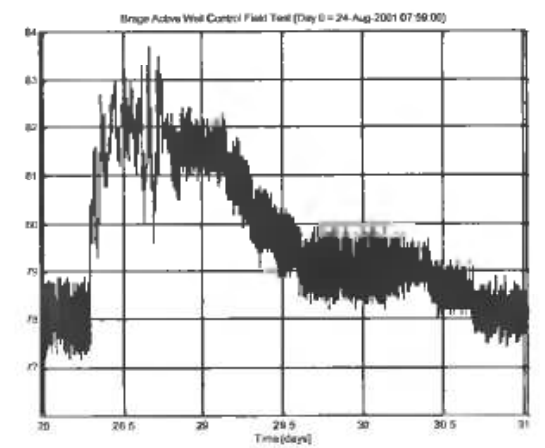

Figure 22. Downhole pressure [bar] corresponding to the choke opening in Figure 21. As the well is operated manually, with constant choke opening, the downhole pressure increases rapidly and begins to oscillate with a higher amplitude and lower frequency. This changes as active well control is put in action again.

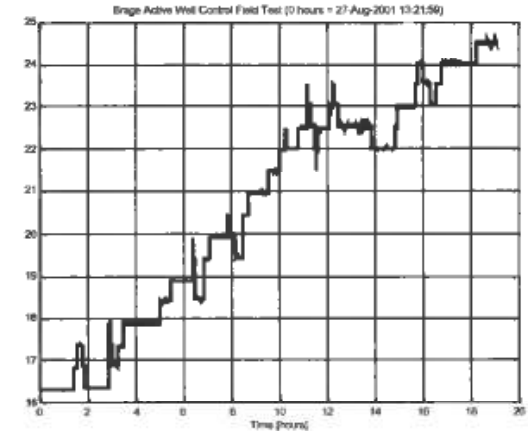

Figure 19. Production Choke opening [\%] corresponding to the decrease of setpoint in Figure 18.

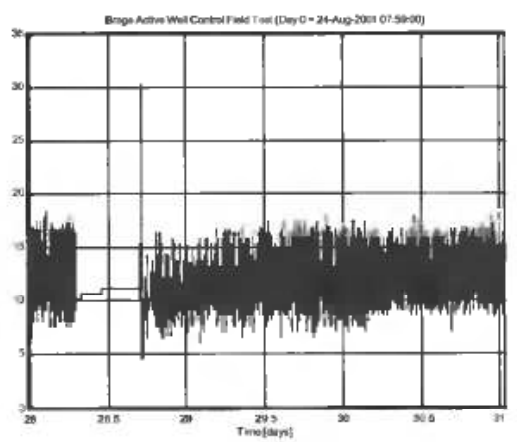

Figure 21. Choke opening [\%]. As a test, the well is operated manually for a period of time. resulting in constant choke opening.

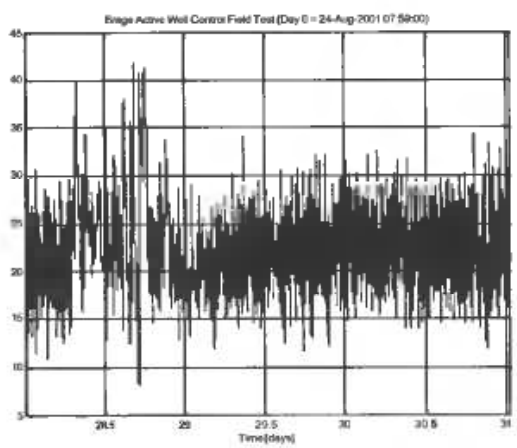

Figure 23. Wellhead pressure [bar] corresponding to Figure 22 . 


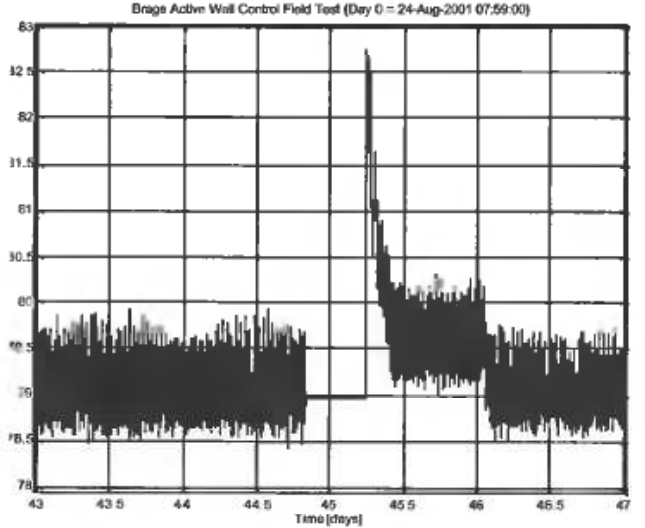

Figure 24. Downhole pressure [bar]. Just before time $=45$ Days, a loss of the downhole pressure measurement is encountered. This is reflected by a moer or less constant signal to the active well controller.

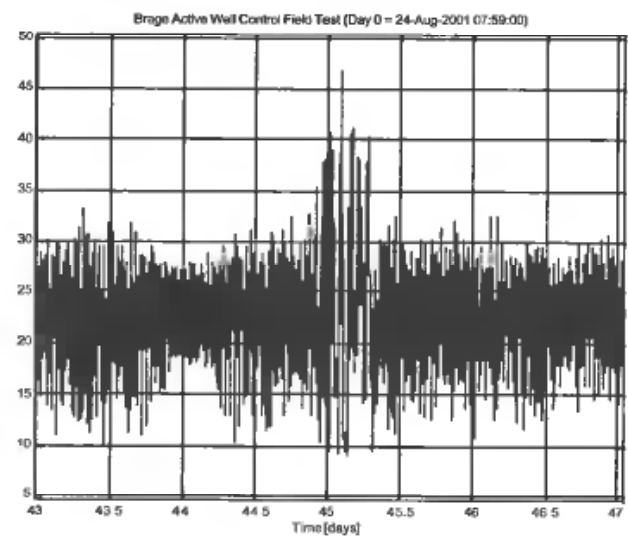

Figure 26. Wellhead pressure [bar] corresponding to the loss of the downhole pressure measurement in Figure 24 and Figure 25. The amplitude of the wellhead pressure oscillations increases sharply as a result of the loss of active well control.

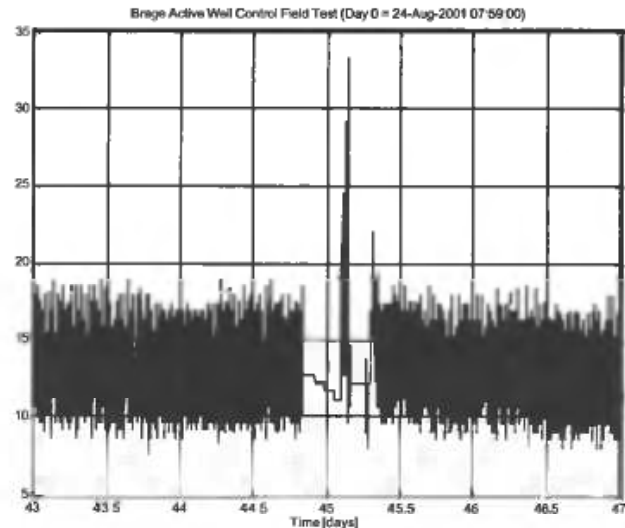

Figure 25. Choke opening [\%] corresponding to the downhole pressure mesurement in Figure 24. As the downhole pressure measurement is lost, the active well controller get a constant downhole pressure as input, resulting in a more or less constant choke opening. As soon as the downhole pressure measurement is available again, the choke starts to control the well actively to calm down the well.

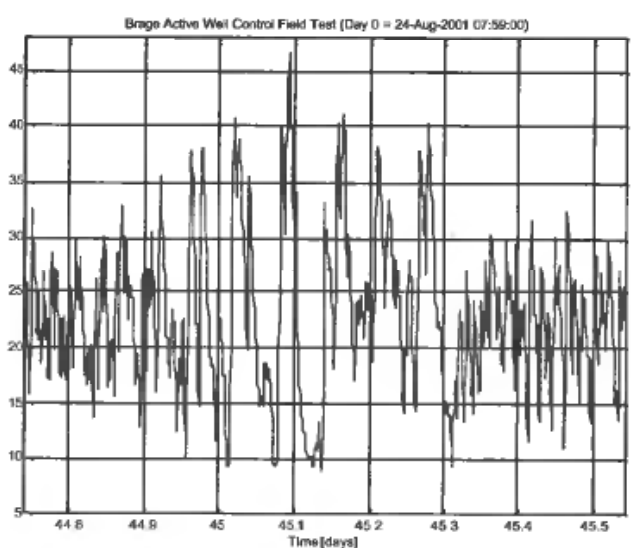

Figure 27. Wellhead pressure [bar] corresponding to the loss of the downhole pressure measurement in Figure 24 and Figure 25. The amplitude of the wellhead pressure oscillations increases sharply as a result of the loss of active well control. 